\title{
Lung ultrasound for ever
}

\section{Christoph F Dietrich}

Department Allgemeine Innere Medizin (DAIM), Kliniken Hirslanden, Beau Site, Salem und Permanence, Bern, Switzerland

The World Federation for Ultrasound in Medicine and Biology (WFUMB) is dedicated to the advancement of ultrasound by encouraging research, promoting international cooperation, disseminating scientific information and improving communication and understanding in the world community using ultrasound in medicine and biology. One mission of WFUMB is to bring sustainable ultrasound programs to the underserved areas of the world to improve global healthcare through collaboration, communication and education (www.wfumb.org). Medical Ultrasonography (formerly Revista Româna de Ultrasonografie from 1999 to 2008) is the official publication of the Romanian Society for Ultrasonography in Medicine and Biology (SRUMB), published in English, quarterly. SRUMB and Med Ultrason are active members in WFUMB and the European Federation of Societies for Ultrasound in Medicine and Biology (EFSUMB) [1].

In the current WFUMB paper series, three consecutive papers are published in Med Ultrason describing the examination technique, applications and practical use of chest, diaphragmatic, pleura, mediastinal and lung ultrasound in children with congenital and acquired diseases. The advantages of ultrasound in pediatric patients are obvious: its high spatial and temporal resolution, real-time imaging, and lack of ionizing radiation and bedside availability at the point of care [2-4]. In addition, new ultrasound technologies have been introduced into chest and lung ultrasound applications including higher resolution transducers and harmonic imaging allowing direct visualization of structures being less dependent on artifacts [5-8]. The use and controversies of lung artefacts have

Received Accepted

Med Ultrason

2022, Vol. 24, No 1, 5-6

Corresponding author: Prof. Dr. med. Christoph F. Dietrich, MBA

Department of Internal Medicine (DAIM)

Kliniken Hirslanden Bern, Beau Site,

Salem and Permanence

Schänzlihalde 11, 3031 Bern, Switzerland

E-mail: c.f.dietrich@googlemail.com been described in Med Ultrason [5,7]. Contrast-enhanced ultrasound (CEUS) ([11] and also to a lesser degree elastography [12] have expanded the roles of LUS. The challenges of CEUS in pediatric patients have been recently reviewed [13-15].

The lack of superficial adipose and bone tissue provides favorable acoustic windows in children compared to the more often more difficult situation in adults due to the presence of a bony thorax makes ultrasound the first line of investigation for evaluation of pleural and chest wall abnormalities in pediatric patients. In a meta-analysis consisting of 1510 children, chest ultrasound shows significantly better sensitivity and similar specificity in detecting pneumonia in children compared to chest radiography [16]. LUS has been proposed as a reasonable alternative first-line investigation for diagnosing suspected community-acquired pneumonia [17].

The first article covers the technical requirements, examination technique, normal sonographic appearance of the pleural space, identifying and determining the type and volume of pleural effusion, pleuritis and diffuse pleural thickening, solid pleural lesions including benign and malignant pleural tumors and fibrogenic changes of the pleura (fibrothorax) [2]. The most important pathologies of the pleural cavity in pediatric patients are pleural effusion and pneumothorax [2].

In the second paper the use of ultrasound in the lung in pediatric patients is described including the interstitial syndrome, bacterial pneumonia and viral infections, COViD findings, atelectasis, lung consolidation, bronchiolitis and congenital diseases of the respiratory system including congenital pulmonary airway malformation (CPAM) and sequester [3]. Severe acute respiratory syndrome (SARS) coronavirus-2 disease (COViD) has been a challenge since 2019. Lung ultrasound allows the identification of typical sonographic signs in the course of COVID-19 infections including the triad of ultrasound features of the pleura and pleural space represented by irregularities, findings of interstitial pneumonia repre- 
sented by subpleural consolidation and B-line artefacts. In addition, contrast enhanced ultrasound depicts typical perfusion defects in COViD-patients compared to other entities $[9,11]$. Extrapulmonary manifestations can be also detected and characterized using ultrasound [18].

In the third article, the use of ultrasound for chest wall, mediastinum, diaphragmatic diseases, trachea, interventions and artifacts in pediatric patients are summarized [4].

In conclusion, the change in attitude and growing awareness of the diagnostic possibilities has led to lung ultrasound being accepted as a valuable point of care method and is supported by international societies including EFSUMB and WFUMB [19-22].

\section{References}

1. Piscaglia F, Stefanini F, Cantisani V, et al. Benefits, Open questions and Challenges of the use of Ultrasound in the COVID-19 pandemic era. The views of a panel of worldwide international experts. Ultraschall Med 2020;41:228236.

2. Jaworska J, Buda N, Ciuca IM, et al. Ultrasound of the pleura in children, WFUMB review paper. Med Ultrason 2021;23:339-347.

3. Dietrich CF, Buda N, Ciuca IM, et al. Lung ultrasound in children, WFUMB review paper (part 2). Med Ultrason 2021;23:443-452.

4. Fang C, Jaworska J, Buda N, et al. Ultrasound of the chest and mediastinum in children, interventions and artefacts. WFUMB review paper (part 3). Med Ultrason 2022;24: 65-76.

5. Mathis G, Horn R, Morf S, et al. WFUMB position paper on reverberation artefacts in lung ultrasound: B-lines or comet-tails? Med Ultrason 2021;23:70-73.

6. Yue Lee FC, Jenssen C, Dietrich CF. A common misunderstanding in lung ultrasound: the comet tail artefact. Med Ultrason 2018;20:379-384.

7. Dietrich CF, Mathis G, Blaivas M, et al. Lung artefacts and their use. Med Ultrason 2016;18:488-499.

8. Dietrich CF, Mathis G, Blaivas M, et al. Lung B-line artefacts and their use. J Thorac Dis 2016;8:1356-1365.

9. Safai Zadeh E, Beutel B, Dietrich CF, et al. Perfusion Patterns of Peripheral Pulmonary Lesions in COVID-19 Patients Using Contrast-Enhanced Ultrasound (CEUS): A Case Series. J Ultrasound Med 2021;40:2403-2411.
10. Safai Zadeh E, Görg C, Dietrich CF, Görlach J, Alhyari A, Trenker C. Contrast-enhanced ultrasound for evaluation of pleural effusion: a pictorial essay. J Ultrasound Med 2022;41:485-503.

11. Safai Zadeh E, Westhoff CC, Keber CU, et al. Perfusion Patterns of Peripheral Organizing Pneumonia (POP) Using Contrast-Enhanced Ultrasound (CEUS) and Their Correlation with Immunohistochemically Detected Vascularization Patterns. Diagnostics (Basel) 2021;11:1601.

12. Dietrich CF, Ferraioli G, Sirli R, et al. General advice in ultrasound based elastography of pediatric patients. Med Ultrason 2019;21:315-326.

13. Dietrich CF, Averkiou M, Nielsen MB, et al. How to perform Contrast-Enhanced Ultrasound (CEUS). Ultrasound Int Open 2018;4:E2-E15.

14. Sidhu PS, Cantisani V, Deganello A, et al. Role of Contrast-Enhanced Ultrasound (CEUS) in Paediatric Practice: An EFSUMB Position Statement. Ultraschall Med 2017;38:33-43.

15. Dietrich CF, Augustiniene R, Batko T, et al. European Federation of Societies for Ultrasound in Medicine and Biology (EFSUMB): An Update on the Pediatric CEUS Registry on Behalf of the "EFSUMB Pediatric CEUS Registry Working Group". Ultraschall Med 2021;42:270-277.

16. Balk DS, Lee C, Schafer J, et al. Lung ultrasound compared to chest X-ray for diagnosis of pediatric pneumonia: A meta-analysis. Pediatr Pulmonol 2018;53:1130-1139.

17. Stadler JAM, Andronikou S, Zar HJ. Lung ultrasound for the diagnosis of community-acquired pneumonia in children. Pediatr Radiol 2017;47:1412-1419.

18. Dehmani S, Penkalla N, Jung EM, et al. Scoping Review: Sonographic evidence of intraabdominal manifestations of COVID-19. Med Ultrason 2022. doi:10.11152/mu-3538

19. Dietrich CF, Mathis G, Cui XW, Ignee A, Hocke M, Hirche TO. Ultrasound of the pleurae and lungs. Ultrasound Med Biol 2015;41:351-365.

20. Dietrich CF, Goudie A, Chiorean L, et al. Point of Care Ultrasound: A WFUMB Position Paper. Ultrasound Med Biol 2017;43:49-58.

21. Soldati G, Smargiassi A, Inchingolo R, et al. Proposal for International Standardization of the Use of Lung Ultrasound for Patients With COVID-19: A Simple, Quantitative, Reproducible Method. J Ultrasound Med 2020;39:14131419.

22. Volpicelli G, Elbarbary M, Blaivas M, et al. International evidence-based recommendations for point-of-care lung ultrasound. Intensive Care Med 2012;38:577-591. 